\title{
Fool Me Twice: The Role for Hospitals and Health Systems in Fixing the Broken PPE Supply Chain
}

\author{
Tara Lagu, MD, MPH ${ }^{1,2 *}$, Andrew W Artenstein, MD², Rachel M Werner, MD, PhD 3,4
}

${ }^{1}$ Institute for Healthcare Delivery and Population Science, Baystate Health, Springfield, Massachusetts; ${ }^{2}$ Department of Medicine, University of Massachusetts Medical School-Baystate, Springfield, Massachusetts; ${ }^{3}$ Leonard Davis Institute of Health Economics, University of Pennsylvania, Philadelphia, Pennsylvania; ${ }^{4}$ Department of Medicine, Perelman School of Medicine, University of Pennsylvania, Philadelphia, Pennsylvania.

T

he story of the coronavirus disease 2019 (COVID-19) pandemic in the United States has been defined, in part, by a persistent shortage of medical supplies that has made it difficult and dangerous for healthcare workers to care for infected patients. States, health systems, and even individual hospitals are currently competing against one another-sometimes at auction - to obtain personal protective equipment (PPE). This "Wild West" scenario has resulted in bizarre stories involving attempts to obtain PPE. One health system recently described a James Bond-like pursuit of essential PPE, complete with a covert trip to an industrial warehouse, trucks filled with masks but labeled as food delivery vehicles, and an intervention by a United States congressman. ${ }^{1}$ Many states have experienced analogous, but still atypical, stories: masks flown in from China using the private jet of a professional sports team owner, ${ }^{2}$ widespread use of novel sterilization modalities to allow PPE reuse, ${ }^{3}$ and one attempt to purchase price-gouged PPE from the host of the show "Shark Tank." ${ }^{4}$ In some cases, hospitals and healthcare workers have pleaded for PPE on fundraising and social media sites. ${ }^{5}$

These profound deviations from operations of contemporary health system supply chains would have seemed beyond belief just a few months ago. Instead, they now echo the collective experiences of healthcare stakeholders trying to obtain PPE to protect their frontline healthcare workers during the COVID-19 pandemic.

\section{HEALTHCARE MARKETS DURING A PANDEMIC}

How did we get into this situation? The manufacture of medical supplies like gowns and masks is a highly competitive business with very slim margins, and as a result, medical equipment manufacturers aim to match their supply with the market's demand, with hospitals and health systems using justin-time ordering to limit excess inventory. ${ }^{6}$ While this approach adds efficiency and reduces costs, it also renders manufacturers and customers vulnerable to supply disruptions and shortages when need surges. The COVID-19 pandemic represents

*Corresponding Author: Tara Lagu, MD, MPH; Email: Tara.Lagu@ baystatehealth.org; Telephone: 413-794-7688 Twitter: @taralagumd.

Published online first August 19, 2020.

Received: May 29, 2020; Revised: June 9, 2020; Accepted: June 12, 2020

(๑) 2020 Society of Hospital Medicine DOI 10.12788/jhm.3489 perhaps the most extreme example of a massive, widespread surge in demand that occurred multifocally and in a highly compressed time frame. Unlike other industries (eg, consumer paper products), however, in which demand exceeding supply causes inconvenience, the lack of PPE has led to critical public health consequences, with lives of both healthcare workers and vulnerable patients lost because of these shortages of medical equipment.

\section{THE SPECIAL CASE OF PPE}

There are many reasons for the PPE crisis. As noted above, manufacturers have prioritized efficiency over the ability to quickly increase production. They adhere to just-in-time ordering rather than planning for a surge in demand with extra production capacity, all to avoid having warehouses filled with unsold products if surges never occur. This strategy, compounded by the fact that most PPE in the United States is imported from areas in Asia that were profoundly affected early on by COVID-19, led to the observed widespread shortages. When PPE became unavailable from usual suppliers, hospitals were unable to locate other sources of existing PPE because of a lack of transparency about where PPE could be found and how it could be obtained. The Food and Drug Administration and other federal regulatory agencies maintained strict regulations around PPE production and, despite the crisis, made few exceptions. ${ }^{7}$ The FDA did grant a few Emergency Use Authorizations (EUAs) for certain improvised, decontaminated, or alternative respirators (eg, the Chinese-made KN95), but it has only very infrequently issued EUAs to allow domestic manufacturers to ramp up production. ${ }^{8}$ These failures were accompanied by a serious increase in PPE use, leading to spikes in price, price gouging, and hoarding, ${ }^{9}$ problems that were further magnified as health systems and hospitals were forced to compete with nonhealthcare businesses for PPE.

\section{LACK OF FEDERAL GOVERNMENT RESPONSE}

The Defense Production Act (DPA) gives the federal government the power to increase production of goods needed during a crisis ${ }^{8}$ to offer purchasing guarantees, coordinate federal agencies, and regulate distribution and pricing. However, the current administration's failure to mount a coordinated federal response has contributed to the observed market instability, medical supply shortages, and public health crisis we face. We have previously recommended that the federal government use the power of the DPA to reduce manufacturers' 
risk of being uncompensated for excess supply, support temporary reductions in regulatory barriers, and create mandatory centralized reporting of PPE supply, including completed PPE and its components. ${ }^{10}$ We stand by these recommendations but also acknowledge that hospitals and health systems may be simultaneously considering how to best prepare for future crises and even surges in demand over the next 18 months as the COVID-19 pandemic continues.

\section{RECOMMENDATIONS FOR HEALTH SYSTEMS AND HOSPITALS}

1. Encourage mandates at the hospital, health system, and state level regarding minimum inventory levels for essential equipment. Stockpiles are essential for emergency preparedness. In the long term, these sorts of stockpiles are economically infeasible without government help to maintain them. In the near term, however, it is sensible that hospitals and health systems would maintain a minimum of 2 weeks' worth of PPE to prepare for expected regional spikes in COVID-19 cases. However, a soon-to-published study suggests that over $40 \%$ of hospitals had a PPE stockpile of less than 2 weeks. ${ }^{11}$ Although this survey was conducted at the height of the shortage, it suggests that there is opportunity for improvement.

2. Coordinate efforts among states and health systems to collect and report inventory, regionalize resources, and coordinate their distribution. The best example of this is the seven-state purchasing consortium announced by New York Governor Andrew Cuomo in early May. ${ }^{12}$ Unfortunately, since the announcement, there have been few details about whether the states were successful in their effort to reduce prices or to obtain PPE in bulk. Still, hospitals and health systems could join or emulate purchasing collaboratives to allow resources to be better allocated according to need. There are barriers to such collaboratives because the market is currently set up to encourage competition among health systems and hospitals. During the pandemic, however, cooperation has increasingly been favored over competition in science and healthcare delivery. There are also existing hospital purchasing collaboratives (eg, Premier, Inc ${ }^{13}$ ), which have taken steps to vet suppliers and improve access to PPE, but it is not clear how successful these efforts have been to date.

3. Advocate for strong federal leadership, including support for increased domestic manufacturing; replenishment and maintenance of state and health system stockpiles of PPE, ventilators, and medications; and development of a centrally coordinated PPE allocation and distribution process. While hospitals and health systems may favor remaining as apolitical as possible, the need for a federal response to stabilize the PPE market may be too urgent and necessary to ignore.

\section{CONCLUSION}

As hospitals and health systems prepare for continued surges in COVID-19 cases, they face challenges in providing PPE for frontline clinicians and staff. A federal plan to enhance nimbleness in responding to multifocal, geographic outbreaks and ensure awareness regarding inventory would improve our chances to successfully navigate the next pandemic and optimize the protection of our health workers, patients, and public health. In the absence of such a plan, hospitals should maintain a minimum of 2 weeks' worth of PPE to prepare for expected regional spikes in COVID-19 cases and should continue to attempt to coordinate efforts among states and health systems to collect and report inventory, regionalize resources, and coordinate their distribution.

Disclosures: Dr Lagu reported personal fees from the Yale Center for Outcomes Research and Evaluation under contract to the Centers for Medicare \& Medicaid Services (CMS). The views expressed in this article do not necessarily reflect those of the Yale Center or CMS. The other authors had nothing to disclose.

Funding: Dr Lagu received grant support from the National Heart, Lung, and Blood Institute of the National Institutes of Health (R01 HL139985-01A1 and 1R01HL146884-01).

\section{References}

1. Artenstein AW. In pursuit of PPE. N Engl J Med. 2020;382(18):e46. https:// doi.org/10.1056/nejmc2010025

2. McGrane V, Ellement JR. A Patriots plane full of 1 million N95 masks from China arrived Thursday. Here's how the plan came together. Boston Globe. Updated April 2, 2020. Accessed April 27, 2020. https://www.bostonglobe. com/2020/04/02/nation/kraft-family-used-patriots-team-plane-shuttle -protective-masks-china-boston-wsj-reports/

3. Kolodny L. California plans to decontaminate 80,000 masks a day for health workers amid the COVID-19 pandemic. CNBC. April 8, 2020. Updated April 9,2020. Accessed April 27, 2020. https://www.cnbc.com/2020/04/08/california -plans-to-sanitize-80000-n95-masks-a-day-for-health-workers.html

4. Levenson M. Company questions deal by 'Shark Tank' star to sell N95 masks to Florida. New York Times. April 22, 2020. Accessed May 20, 2020. https:// www.nytimes.com/2020/04/22/us/daymond-john-n95-masks-florida-3m.html

5. Padilla M. 'It feels like a war zone': doctors and nurses plead for masks on social media. New York Times. March 19, 2020. Updated March 22, 2020. Accessed April 27, 2020. https://www.nytimes.com/2020/03/19/us/hospitals -coronavirus-ppe-shortage.html

6. Lee $\mathrm{HL}$, Billington $\mathrm{C}$. Managing supply chain inventory: pitfalls and opportunities. MIT Sloan Management Review. April 15, 1992. Accessed April 27, 2020. https://sloanreview.mit.edu/article/managing-supply-chain-inventory-pitfalls-and-opportunities/

7. Emergency Situations (Medical Devices): Emergency Use Authorizations. Food and Drug Administration. Accessed May 10, 2020. https://www.fda. gov/medical-devices/emergency-situations-medical-devices/emergency -use-authorizations

8. Watney C, Stapp A. Masks for All: Using Purchase Guarantees and Targeted Deregulation to Boost Production of Essential Medical Equipment. Mercatus Center: George Mason University. April 8, 2020. Accessed June 23, 2020. https://www.mercatus.org/publications/covid-19-crisis-response /masks-all-using-purchase-guarantees-and-targeted-deregulation

9. Volkov M. DOJ hoarding and price gouging task force seizes critical medical supplies and distributes to New York and New Jersey hospitals. Corruption, Crime \& Compliance blog. April 2, 2020. Accessed April 27, 2020. https:// blog.volkovlaw.com/2020/04/doj-hoarding-and-price-gouging-task-forceseizes-critical-medical-supplies-and-distributes-to-new-york-and-new-jersey-hospitals/

10. Lagu T, Werner R, Artenstein AW. Why don't hospitals have enough masks? Because coronavirus broke the market. Washington Post. May 21, 2020. Accessed May 25, 2020. https://www.washingtonpost.com/outlook/2020/05/21 /why-dont-hospitals-have-enough-masks-because-coronavirus-brokemarket/

11. Auerbach $A, O^{\prime}$ Leary KJ, Harrison JD, et al. Hospital ward adaptation during the COVID-19 Pandemic: a national survey of academic medical centers. J Hosp Med. 2020;15:483-488. https://doi.org/10.12788/jhm.3476

12. Voytko L. NY will team up with 6 states to buy medical supplies, Cuomo says. Forbes. May 3, 2020. Accessed May 26, 2020. https://www.forbes.com/sites /lisettevoytko/2020/05/03/ny-will-team-up-with-6-states-to-buy-medicalsupplies-cuomo-says/

13. Premier. Supply Chain Solutions. Accessed May 26, 2020. https://www .premierinc.com/solutions/supply-chain 